\title{
An integrated 3-D model for wave-induced seabed response in a porous seabed. I. a sloping seabed
}

\author{
H. Zhang ${ }^{1}$ and D.-S. Jeng ${ }^{2,3}$ \\ 1 School of Engineering, Griffith University Gold Coast Campus, QLD 9726, Australia \\ 2 Research Institute of Coastal and Ocean Engineering, Hohai University, Nanjing 210098, China \\ 3 Department of Civil Engineering, The University of Sydney, NSW 2006, Australia \\ Email: hong.zhang@griffith.edu.au (H Zhang),d.jeng@civil.usyd.edu.au (DS Jeng)
}

Submitted to Ocean Engineering, 10 March 2004

\begin{abstract}
In this paper, an integrated model for the wave-induced seabed response in a porous seabed is proposed. Most previous studies have considered two-dimensional cases and a flat seabed. In this study, a full three-dimsnional case is considered as well as a sloping seabed. The wave model (SWAN) and soil model (PORO-WSI) is coupled into one model. With the new model, the effects of wave and soil characteristics on the ocean waves-induced seabed response (including pore pressure and stresses) are investigated. Based on numerical results, the following conclusions can be drawn: (1) the magnitude of the wave-induced soil response in a sloping seabed is much smaller than that in a flat seabed (2) the wave-induced pore pressure decreases as the slope of the seabed increases.
\end{abstract}

Keywords: Wave model, soil model, seabed response, pore pressures, effective stresses.

\section{Introduction}

Considerable effort has been devoted to the wave-soil-structure interaction phenomenon in the past three decades. The major reason for the growing interest is that many coastal structures (such as vertical walls, caissons, pipelines, etc.) have been damaged by the wave-induced seabed response, rather than from construction deficiencies (Christian et al., 1974; Lundgren et al., 1989). It is common to observe that concrete armor blocks at the toes of many marine structures have been found to subside into the seabed. Wave-induced liquefaction and shear failure have been identified as culprit for this problem (Silvester and Hsu, 1989). Another reason is that the poro-elastic theories for wave-soil interaction have been applied to field measurements, such as the determination of the shear modulus of soil (Yamamoto and Trevorrow, 1991) and the directional spectra of ocean surface waves (Nye and Yamamoto, 1994), as well as acoustic wave propagating through porous media (Yamamoto and Turgut, 1988).

When water waves propagate in the ocean, they generate significant dynamic pressures on the sea floor. This pressure field induces pore water pressure and effective stresses within the seabed. With excess pore-pressure and diminishing vertical effective stress, part of the seabed may become unstable or even liquefied. Once liquefaction occurs, the soil particles are likely to be carried away as a fluid by any prevailing bottom current or mass transport owing to the action of ocean waves.

The occurrence of seabed instability is a widespread phenomenon in ocean environments (Silvester and Hsu, 1993). There is evidence of ocean floor instability in a wide variety of offshore regions, from shallow water, near-shore zones, continental slopes and beyond to deep ocean floors. Seabed instability has been responsible for the damage and destruction of offshore structures (Christian et al., 1974; Bea et al., 1983; Barends, 1991).

Although the phenomenon of wave-induced seabed instability has received great attention among coastal and geotechnical engineers since 1970's, preliminary experiments and theories for such a problem have only been available for two-dimensional progressive waves. Recently, significant progress has been made towards the development of both analytical and numerical approaches for some simple modes of instability in a porous seabed. However, to date, a three-dimensional model integrating wave and soil components, providing a better understanding for coastal geotechnical engineers, has not been available. 
This paper is the first of the series papers. The non-breaking wave-induced seabed response will be investigated in this paper, while the breaking wave-induced seabed response will be discussed in the second paper (Jeng and Zhang, 2004). In this paper, A brief of previous investigations of wave-induced seabed response will be given first. Then, an integrated model (wave and soil models) will be established for the case of non-breaking waves loading. A parametric study for the effects of various wave and soil characteristics on the wave-induced pore pressure and effective stresses will be conducted.

\section{Theoretical Formulations}

\section{$2.1 \quad$ Wave model}

SWAN is a numerical model, which provides estimates of the wave parameters in coastal areas, lakes and estuaries with given wind, bottom and current conditions. It is a spectral wave model based on the action density balance equation (Booij et al., 1999; Ris et al., 1999), which calculates wave transformation and set up. The version (Cycle 3, version 40.20) used in present study is the time dependent version released to public in 2003. It takes into account the wind wave growth, dissipation by white-capping, bottom friction and wave breaking. The quadruplets and triads wave-wave interactions are also included. Furthermore, the model can simulate the wave propagation processes such as, propagation through geographic space, refraction due to spatial variations in bottom and current, shoaling due to spatial variations in bottom and current, blocking and reflections by opposing currents, and transmission through, blocked by or reflection against sub-grid obstacles.

In SWAN the evolution of the wave spectrum is described by the spectral action balance equation, which for spherical coordinates is (Holthuijsen et al., 2003):

$$
\frac{\partial N}{\partial t}+\frac{\partial c_{\lambda} N}{\partial \lambda}+(\cos \varphi)^{-1} \frac{\partial c_{\varphi} N}{\partial \varphi}+\frac{\partial c_{\sigma} N}{\partial \sigma}+\frac{\partial c_{\theta} N}{\partial \theta}=\frac{S}{\sigma}
$$

with longitude, $\lambda$; latitude, $\varphi$; the wave direction (the direction normal to the wave crest of each spectral $\theta$ component); the relative frequency (as observed in a frame of reference moving $\sigma$ with current velocity); action density spectrum, $N(\sigma, \theta)$; propagation velocities and in $\lambda, \varphi, \theta$ and $\sigma$ space, $c_{\lambda}, \sim c_{\varphi}, c_{\theta}$ and $c_{\sigma}$; the source term in terms of energy density representing effects of generation, dissipation and nonlinear wave-wave interactions. In present study, the main corresponding input source is wind energy as:

$$
S_{\text {in }}=A+B E(\sigma, \theta)
$$

where $A$ and $B$ depend on wave frequency and direction, and wind speed and direction. The dissipation of white capping and bottom friction are considered, but the depth induce breaking is not taken into account.

The dissipation form of wave energy can be expressed in terms of three different contributions. They are: whitecapping, $S_{d s, w}(\sigma, \theta)$, bottom friction $S_{d s, b}(\sigma, \theta)$ and depth-induced breaking $S_{d s, b r}(\sigma, \theta)$. Among these, the whitecapping is controlled by the steepness of the waves, which is based on a pulse-based model, as adopted in the new version of SWAN model, as

$$
S_{d s, w}(\sigma, \theta)=-\Gamma \tilde{\sigma} \frac{k}{\tilde{k}} E(\sigma, \theta)
$$

where $\Gamma$ is a steepness dependent coefficient, $k$ is wave number, and $\tilde{\sigma}$ and $\tilde{k}$ denote a mean frequency and a mean wave number, respectively.

In general, depth-induced dissipation may be caused by bottom friction and motion, by percolation or by back-scattering on bottom irregularities (Shemdin et al., 1978). The dominant mechanism appears to be bottom friction, which can generally be represented as

$$
S_{d s, b}(\sigma, \theta)=-C_{\text {bottom }} \frac{\sigma^{2}}{g^{2} \sinh ^{2}(k d)} E(\sigma, \theta),
$$


where $C_{\text {bottom }}$ is a bottom friction coefficient.

In SWAN model, the dissipation contributed by depth-induced wave breaking has been formulated by a spectral version of the bore model of Battjes and Janssen (1978), which converses the spectral shape (Eldeberky and Battjes, 1995; 1996). The expression used in SWAN is

$$
S_{d s, b r}(\sigma, \theta)=\frac{D_{t o t}}{E_{t o t}} E(\sigma, \theta),
$$

in which $E_{t o t}$ is the total wave energy and $D_{\text {tota }}$ is the rate of dissipation of the total energy due to wave breaking (Battjes and Janssen, 1978).

\subsection{Soil model}

Numerous investigations for wave-induced soil response in a porous seabed, including pore pressure and effective stresses, have been carried out since the 1970s. Among these, three types of governing equations have been used:

- Laplace equation: This is based on the assumption of incompressible pore fluid and soil matrix, which is an uncouple analysis. This model has been used as the first approximation of this problem (Putnam, 1949; Liu, 1973).

- Diffusion equation: The assumption of this approach is the compressible fluid in incompressible soil matrix, which is particularly applicable for fine sand (Moshagen and Torum, 1975).

- Biot's Consolidation equation: This model considers that both pore fluid and soil matrix is compressible, which is a couple analysis. This model has been first proposed by Yamamoto et al. (1978) for simple quasti-static soil behaviour, and has been further applied to the problem of wave-seabedstructure interaction (Mei and Foda, 1981; Jeng, 1997; Kumagai and Foda, 2002). Recently, this model has been further extended to dynamic soil behaviour (Cha, 2002; Cha et al., 2003; Jeng and Cha, 2003).

In this section, the poro-elastic model proposed by Jeng (1997) will be outlined. The Biot's consolidation equation is used as the governing equation of soil model. Some basic assumptions for the wave and soil properties are necessary for establish the soil model. They are:

(1) The horizontal porous seabed is elastically isotropic, hydraulically anisotropic and with a high degree of partially saturation.

(2) The soil skeleton and pore fluid are compressible.

(3) The inertial effects of sediments is neglected in this study.

(4) The soil skeleton generally obeys Hooke's law.

(5) The flow in the porous bed obeys Darcy's law.

(6) The wave pressure on the seabed surface is considered as the only external loading force in the wave-seabed interaction. This implies that the effect of boundary layer is ignored in this study.

Since water waves normally produce a very slow propagating velocity through a sandy seabed, compared with that of shear waves, inertial forces are negligibly small compared with elastic forces in the equations of motion. Mynett and Mei (1982) proved this assumption through a dimensional analysis. Thus, assumption (3) is acceptable for the problem of porous flow in a sandy seabed.

Regarding assumption (6), it has been well documented that wave boundary layer only concentrates on a thin layer above the seabed surface. Compared with the order of wave pressure, it may be negligibly small in a laminar boundary layer, as discussed in Appendix A.

For assumption (7), linear wave theory is commonly used as a first approximation in engineering practice. However, it has been agreed that it has its limits of application. The influence of non-linear wave components on the wave-induced soil response has been dealt with by Jeng and Lin (1997) using a finite element method and Jeng et al. (2004) using a semi-analytical approximation.

The consolidation equation (Biot, 1941) and storage equation (Verruijt, 1969) are generally accepted as those governing the flow of compressible pore fluid in a compressible porous medium. For a threedimensional problem, and treating the porous bed as hydraulically anisotropic, with permeabilities $K_{x}$, $K_{y}$ and $K_{z}$ in the $x-, y$ - and $z$-directions, respectively, the governing equation can be expressed as 


$$
\frac{K_{x}}{K_{z}} \frac{\partial^{2} p}{\partial x^{2}}+\frac{K_{y}}{K_{z}} \frac{\partial^{2} p}{\partial y^{2}}+\frac{\partial^{2} p}{\partial z^{2}}-\frac{\gamma_{w} n^{\prime} \beta}{K_{z}} \frac{\partial p}{\partial t}=\frac{\gamma_{w}}{K_{z}} \frac{\partial \varepsilon}{\partial t},
$$

where $p$ is the wave-induced pore pressure; $\gamma_{w}$ is the unit weight of the pore-water; $n^{\prime}$ is the soil porosity; and $\varepsilon$ is the volume strain defined by

$$
\varepsilon=\frac{\partial u}{\partial x}+\frac{\partial v}{\partial y}+\frac{\partial w}{\partial z}
$$

where $u, v$ and $w$ are the soil displacements in the $x$-, $y$-, and $z$-directions, respectively.

The compressibility of the pore fluid, $\beta$, is related to the apparent bulk modulus of the pore fluid $K^{\prime}$ and the degree of saturation $S_{r}$ (Verruijt, 1969), such that

$$
\beta=\frac{1}{K^{\prime}}=\frac{1}{K_{w}}+\frac{1-S_{r}}{P_{w o}},
$$

where $K_{w}$ is the true bulk modulus of elasticity of water (which may be taken as $1.95 \times 10^{9} \mathrm{~N} / \mathrm{m}^{2}$, Yamamoto et al., 1978), $P_{w o}$ is the absolute water pressure. If the soil skeleton is completely air-free, i.e. fully saturated, then $\beta=1 / K_{w}$, since $S_{r}=1$.

The equations for overall equilibrium in a poro-elastic medium, relating to the effective stresses and pore pressure, are given by

$$
\begin{aligned}
& \frac{\partial \sigma_{x}^{\prime}}{\partial x}+\frac{\partial \tau_{x y}}{\partial y}+\frac{\partial \tau_{x z}}{\partial z}=\frac{\partial p}{\partial x} \\
& \frac{\partial \tau_{x y}}{\partial x}+\frac{\partial \sigma_{y}^{\prime}}{\partial y}+\frac{\partial \tau_{y z}}{\partial z}=\frac{\partial p}{\partial y} \\
& \frac{\partial \tau_{x z}}{\partial x}+\frac{\partial \tau_{y z}}{\partial y}+\frac{\partial \sigma_{z}^{\prime}}{\partial z}=\frac{\partial p}{\partial z}
\end{aligned}
$$

where Cauchy stress tensor on the adjacent faces of a stress element consists of three effective normal stresses and six shear stress components. The shear stresses are expressed in double subscripts $\tau_{r s}$, denoting the stress in the $s$-direction on a plane perpendicular to the $r$-axis.

Based on the generalized Hooke's law, the relationships between elastic incremental effective stresses and soil displacements are given by

$$
\begin{gathered}
\sigma_{x}^{\prime}=2 G\left[\frac{\partial u}{\partial x}+\frac{\mu}{1-2 \mu} \varepsilon\right] \\
\sigma_{y}^{\prime}=2 G\left[\frac{\partial v}{\partial y}+\frac{\mu}{1-2 \mu} \varepsilon\right] \\
\sigma_{z}^{\prime}=2 G\left[\frac{\partial w}{\partial z}+\frac{\mu}{1-2 \mu} \varepsilon\right] \\
\tau_{x z}=G\left[\frac{\partial u}{\partial z}+\frac{\partial w}{\partial x}\right]=\tau_{z x} \\
\tau_{y z}=G\left[\frac{\partial v}{\partial z}+\frac{\partial w}{\partial y}\right]=\tau_{z y}
\end{gathered}
$$




$$
\tau_{x y}=G\left[\frac{\partial u}{\partial y}+\frac{\partial v}{\partial x}\right]=\tau_{y x}
$$

where the shear modulus $G$ is related to Young's modulus $E$ by the Poisson's ratio $\mu$ in the form of $E / 2(1+\mu)$.

Substituting (12)-(17) into (9)-(11), the equations of force equilibrium become

$$
\begin{gathered}
G \nabla^{2} u+\frac{G}{(1-2 \mu)} \frac{\partial \varepsilon}{\partial x}=\frac{\partial p}{\partial x} \\
G \nabla^{2} v+\frac{G}{(1-2 \mu)} \frac{\partial \varepsilon}{\partial y}=\frac{\partial p}{\partial y}
\end{gathered}
$$

and

$$
G \nabla^{2} w+\frac{G}{(1-2 \mu)} \frac{\partial \varepsilon}{\partial z}=\frac{\partial p}{\partial z},
$$

in the $x$-, $y$ - and $z$-directions, respectively.

It is important to note that the equations of force equilibrium, equations (18)-(20), and the stressstrain relationships, equations (12)-(17), are only valid for an isotropic seabed. For a cross-anisotropic seabed, these equations must be modified, as considered in Lin and Jeng (2000).

\subsection{Boundary conditions}

For a homogeneous soil matrix, mathematical expressions for the wave-induced soil response can be derived, with appropriate boundary conditions. In general, two of these are required for a seabed of infinite and finite thickness, i.e., at a rigid impermeable bottom (BBC: Bottom Boundary Condition) and at the seabed surface (SBC: Surface Boundary Condition).

(a) SBC: Boundary conditions at seabed surface $(z=0)$ :

It is commonly accepted that vertical effective normal stresses and shear stresses vanish at the seabed surface, i.e.

$$
\sigma_{z}^{\prime}=\tau_{x z}=\tau_{y z}=0, \text { at } z=0,
$$

and the pore pressure is equal to the wave pressure at the seabed surface,

$$
p=P_{b}, e^{-i \omega t} \text { at } z=0,
$$

where $P_{b}$ is the wave pressure at the seabed surface, which is determined by the wave model.

(b) BBC: Boundary condition at the bottom $(z=-h$ or $z \rightarrow-\infty)$ :

For the soil resting on an impermeable rigid bottom, zero displacements and no vertical flow occur at the horizontal bottom. For a seabed of infinite thickness,

$$
u=v=w=p=0 \text { as } z \rightarrow-\infty
$$

For a seabed of finite thickness ,

$$
u=v=w=\frac{\partial p}{\partial z}=0 \text { at } z=-h
$$

Herein, the general solution for the wave-induced soil response in a propos seabed of infinite thickness is outlined.

Upon combining these solutions, it renders the complete expressions for the soil displacements as 


$$
\begin{gathered}
u=i m P_{b}\left[\left(C_{0}+C_{1} z\right) e^{k z}+C_{2} e^{\delta z}\right] e^{-i \omega t}, \\
v=-n P_{b}\left[\left(C_{0}+C_{1} z\right) e^{k z}+C_{2} e^{\delta z}\right] e^{-i \omega t}, \\
w=P_{b}\left[\left(C_{0}-\frac{1+2 \lambda}{k} C_{1}+C_{1} z\right) e^{k z}+\frac{\delta}{k} C_{2} e^{\delta z}\right] e^{-i \omega t}
\end{gathered}
$$

The parameters $\delta$ and $\lambda$ are coupled with soil properties and wave characteristics, as given by

$$
\begin{gathered}
\delta^{2}=k^{2}\left(\frac{K_{x}}{K_{z}} m^{2}+\frac{K_{y}}{K_{z}} n^{2}\right)-\frac{i \omega \gamma_{w}}{K_{z}}\left(n^{\prime} \beta+\frac{1-2 \mu}{2 G(1-\mu)}\right), \\
\lambda=\frac{(1-2 \mu)\left\{k^{2}\left(1-\frac{K_{x}}{K_{z}} m^{2}-\frac{K_{y}}{K_{z}} n^{2}\right)+\frac{i \omega \gamma_{w} n^{\prime} \beta}{K_{z}}\right\}}{k^{2}\left(1-\frac{K_{x}}{K_{z}} m^{2}-\frac{K_{y}}{K_{z}} n^{2}\right)+\frac{i \omega \gamma_{w}}{K_{z}}\left(n^{\prime} \beta+\frac{1-2 \mu}{G}\right)} .
\end{gathered}
$$

The wave-induced pore pressure is given by

$$
p=\frac{P_{b}}{1-2 \mu}\left[(1-2 \mu-\lambda) C_{1} e^{k z}+\frac{\left(\delta^{2}-k^{2}\right)(1-\mu)}{k} C_{2} e^{\delta z}\right] e^{-i \omega t}
$$

where the effect of wave obliquity in terms of $\delta$ and $\lambda$ can also be observed.

The effective normal stresses can be determined from equations (12)-(17), rendering

$$
\begin{aligned}
\sigma_{x}^{\prime} & =-P_{b}\left\{\left[m^{2}\left(C_{0}+C_{1} z\right)+\frac{2 \mu \lambda}{1-2 \mu} C_{1}\right] e^{k z}\right. \\
& \left.+\left(k^{2} m^{2}-\frac{\mu\left(\delta^{2}-k^{2}\right)}{k(1-2 \mu)}\right) C_{2} e^{\delta z}\right\} e^{-i \omega t}, \\
\sigma_{y}^{\prime} & =-P_{b}\left\{\left[n^{2}\left(C_{0}+C_{1} z\right)+\frac{2 \mu \lambda}{1-2 \mu} C_{1}\right] e^{k z}\right. \\
& \left.+\left(k^{2} n^{2}-\frac{\mu\left(\delta^{2}-k^{2}\right)}{k(1-2 \mu)}\right) C_{2} e^{\delta z}\right\} e^{-i \omega t}, \\
\sigma_{z}^{\prime} & =P_{b}\left\{\left[k C_{0}+C_{1} k z-\frac{2 \lambda \mu(1-\mu)}{1-2 \mu} C_{1}\right] e^{k z}\right. \\
& \left.+\frac{\left(\delta^{2}(1-\mu)-k^{2} \mu\right)}{k(1-2 \mu)} C_{2} e^{\delta z}\right\} e^{-i \omega t},
\end{aligned}
$$

and the effective shear stresses are given by

$$
\begin{gathered}
\tau_{x z}=i m P_{b}\left(\left[k C_{0}+(k z-\lambda) C_{1}\right] e^{k z}+\delta C_{2} e^{\delta z}\right) e^{-i \omega t} \\
\tau_{y z}=-n P_{b}\left(\left[k C_{0}+(k z-\lambda) C_{1}\right] e^{k z}+\delta C_{2} e^{\delta z}\right) e^{-i \omega t}
\end{gathered}
$$




$$
\tau_{x y}=-i m n k P_{b}\left[\left(C_{0}+C_{1} z\right) e^{k z}+C_{2} e^{\delta z}\right] e^{-i \omega t} .
$$

In equations (25)-(36), the $C_{i}$ coefficients are given by

$$
\begin{gathered}
C_{0}=\frac{-\lambda\left[\mu(\delta-k)^{2}-\delta(\delta-2 k)\right]}{k(\delta-k)(\delta-\delta \mu+k \mu+k \mu+k \lambda)}, \\
C_{1}=\frac{\delta-\delta \mu+k \mu}{\delta-\delta \mu+k \mu+k \mu+k \lambda}, \\
C_{2}=\frac{k \lambda}{(\delta-k)(\delta-\delta \mu+k \mu+k \mu+k \lambda)} .
\end{gathered}
$$

To integrate two models into one, first, we must calculate the wave characteristics (including wave profile, wavelength, water particle velocities and wave pressure at the surface of the seabed). Once we have the wave characteristics, the soil model will be used to determine the wave-induced pore pressure, effective stresses and displacements etc.

\section{$3 \quad$ Numerical Examples}

The objective of this study is to establish an integrated three-dimensional model for the wave-induced pore pressure and effective stresses in a porous seabed. Two new contributions are made in this paper: (1) a fully three-dimensional model, and (2) the seabed is a sloping bottom, rather than flat bottom.

To demonstrate the influence of the above new contributions, the following numerical examples are used. In the numerical examples, the slope of seabed is considered to be $1 / 10$, and the configuration of the seabed bottom is given in Figure 1(a). With this seabed geomography, the wave height, wave direction, wavelength and wave period can be calculated by the wave mode, and illustrated in Figures $1(\mathrm{~b})-(\mathrm{d})$.

The input data used in the following examples are tabulated in Table 1.

\subsection{Temporal variations}

Figures 2-5 illustrate the variation of wave-induced pore pressure in both flat and sloping seabeds with different time intervals. In the examples, two depths are chosen, $z=-1 \mathrm{~m}$ and $z=-5 \mathrm{~m}$. The time intervals used in the figures are $0.25 \mathrm{sec}, 1 \mathrm{sec}, 1.75 \mathrm{sec}, 2.5 \mathrm{sec}, 3.25 \mathrm{sec}, 4.05 \mathrm{sec}, 4.75 \mathrm{sec}$ and $5.5 \mathrm{sec}$, which varies from wave crests to troughs (roughly).

As shown in figure 2 and 3 , the patterns of pore pressure distributions $(p)$ in a flat seabed are different at different time intervals, but they vary within the same order. Comparing Figures 2 and 3, the amplitude of the wave-induced pore pressure in a flat seabed at depth of $z=-5 \mathrm{~m}$ is greater than that at $z=-1$ $\mathrm{m}$ at some time intervals.

The distribution of pore pressure in a sloping seabed is different from that in a flat seabed, as shown in Figure 4 and 5. There is a concentration of pore pressure distribution near the coastlines Also, the order of magnitudes of the wave-induced pore pressure in a sloping seabed is much smaller than that in a flat seabed.

To further investigate the effects of various soil characteristics on the wave-induced soil response in a sloping seabed, three important soil parameters, degree of saturation, shear modulus and permeability will be considered in the following sections. The slopes of seabed will also be discussed. To conduct the parametric study, we consider the location-"X", as shown in Figure 1(a), as an example. 


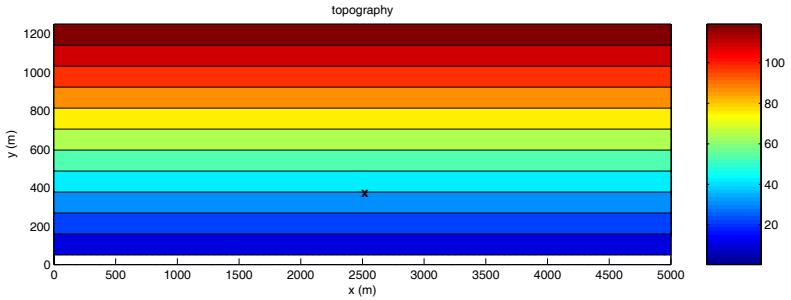

(a) topograph of seabed

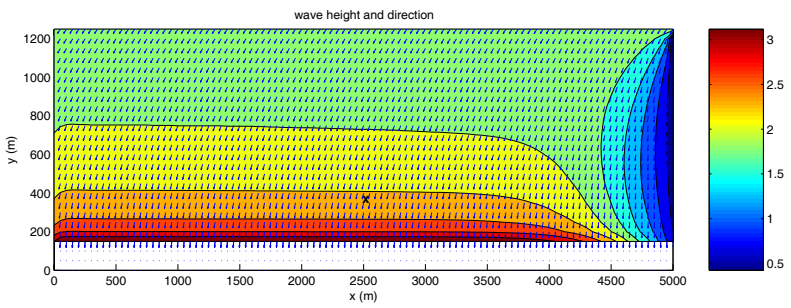

(b) wave heights and direction

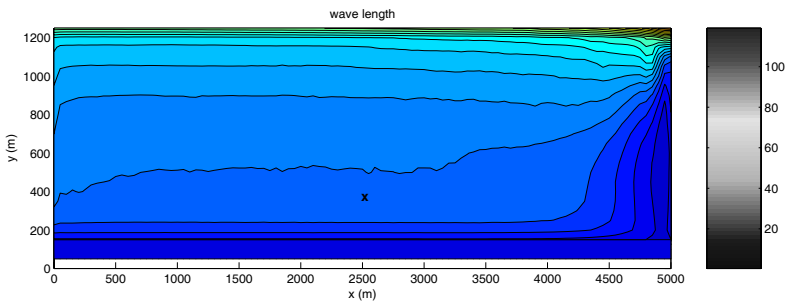

(c) wavelength

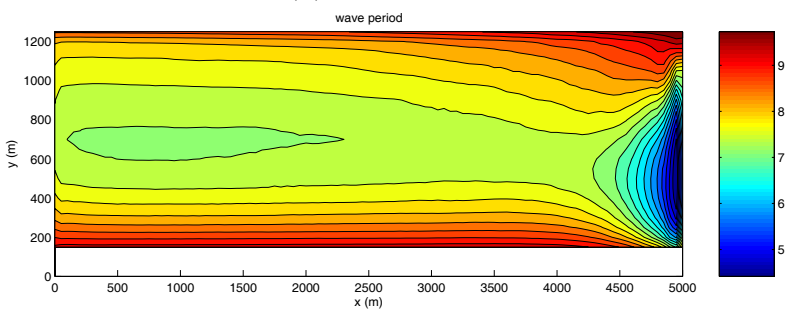

(d) wave periods

Figure 1: (a) Topography of seabed, (b) distribution of wave heights and direction , (c) contour of wavelength and $(\mathrm{d})$ contour of wave periods in a sloping seabed. (slope=1/10) 
Table 1: Input data of numerical model.

\begin{tabular}{|c|c|}
\hline parameters & values \\
\hline grid size in $\mathrm{x}$ direction & $50 \mathrm{~m}$ \\
\hline grid size in y direction & $50 \mathrm{~m}$ \\
\hline grid number in $\mathrm{x}$ direction & 101 \\
\hline grid number in y direction & 26 \\
\hline wind speed & $20 \mathrm{~m} / \mathrm{s}$ \\
\hline wind direction & 225 degree \\
\hline lowest frequency & $0.0521 \mathrm{~Hz}$ \\
\hline highest frequency & $1 \mathrm{~Hz}$ \\
\hline number of frequency & 32 \\
\hline significant wave height at boundaires & $2 m$ \\
\hline peak wave period at boundaries & $10 s$ \\
\hline peak wave direction at boundaries & 225 degree \\
\hline coefficient of soil permeability & $10^{-1}, 10^{-2}, 10^{-4} \mathrm{~m} / \mathrm{s}$ \\
\hline shear modulus of the soil & $5 \times 10^{6}, 10^{7}, 5 \times 10^{7} \mathrm{~N} / \mathrm{m}^{2}$ \\
\hline Poisson's ratio & 0.3 \\
\hline soil porosity & 0.4 \\
\hline bulk modulus of elasticity of water & $2 \times 10^{9} \mathrm{~N} / \mathrm{m}^{2}$ \\
\hline
\end{tabular}

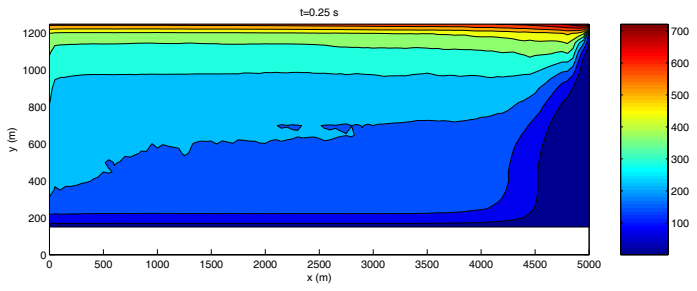

(a) $t=0.25 \mathrm{sec}$

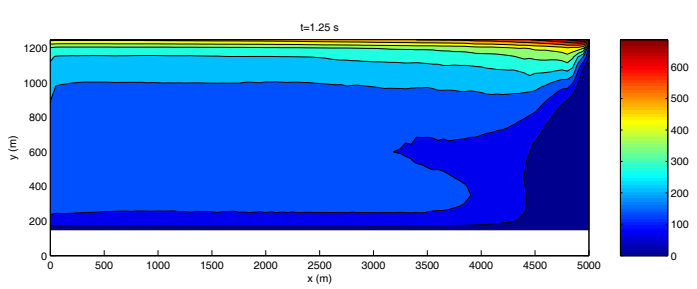

(c) $t=1.75 \mathrm{sec}$

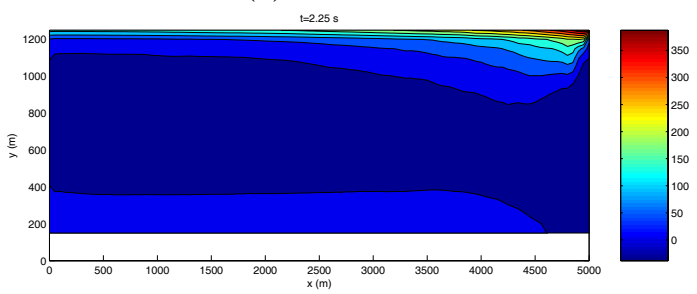

(e) $t=3.25 \mathrm{sec}$

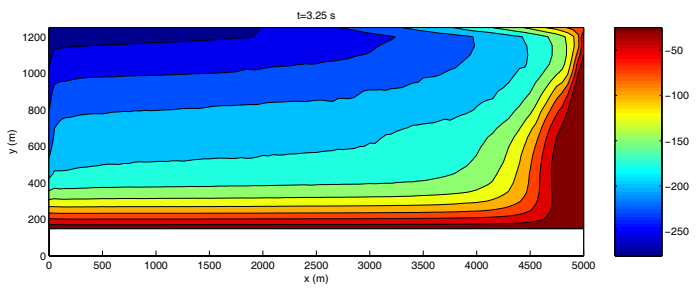

(g) $t=4.75 \mathrm{sec}$

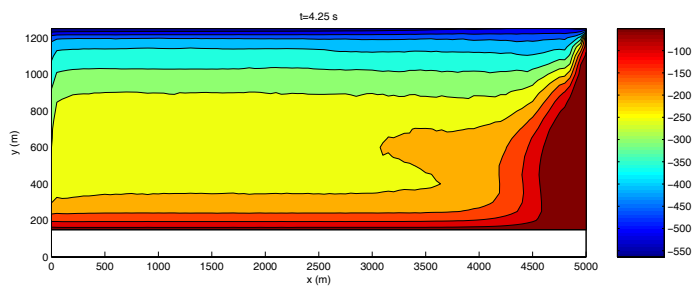

(b) $t=1.0 \mathrm{sec}$

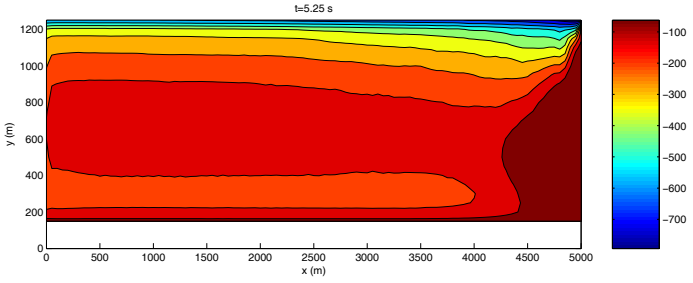

(d) $t=2.5 \mathrm{sec}$

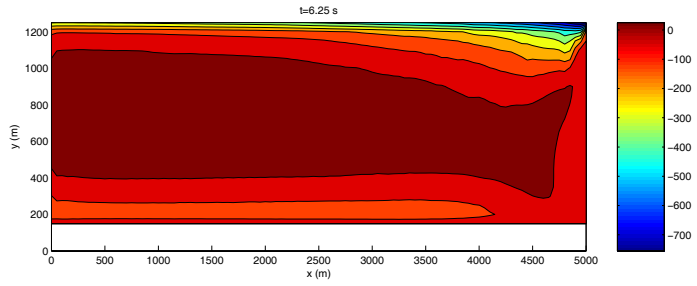

(f) $t=4.0 \mathrm{sec}$

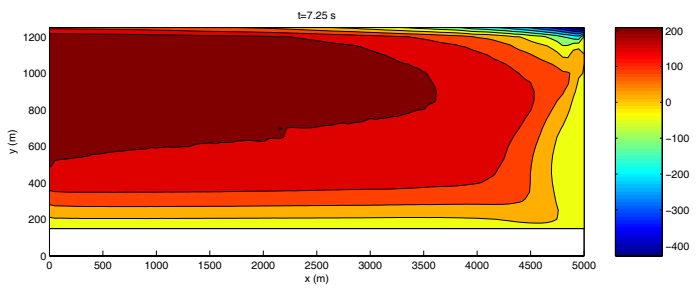

(h) $t=5.5 \mathrm{sec}$

Figure 2: Contour of the wave-induced pore pressure in a flat seabed. $\left(S_{r}=0.95, z=-1 \mathrm{~m}\right)$ 


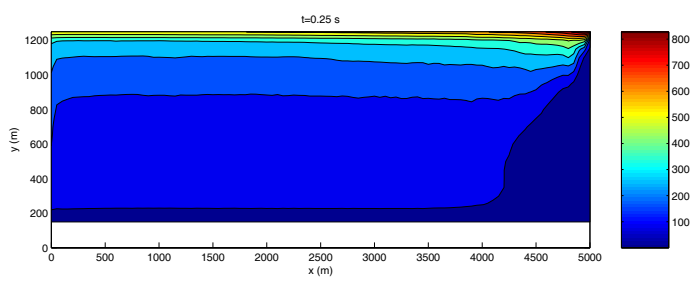

(a) $t=0.25 \mathrm{sec}$

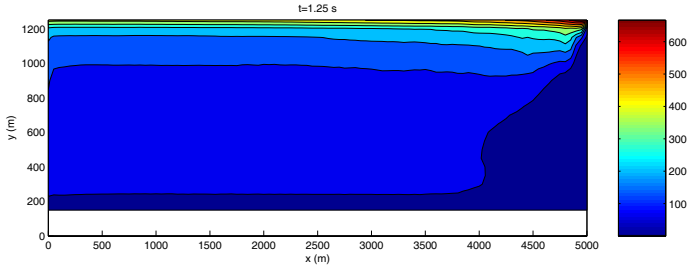

(c) $t=1.75 \mathrm{sec}$

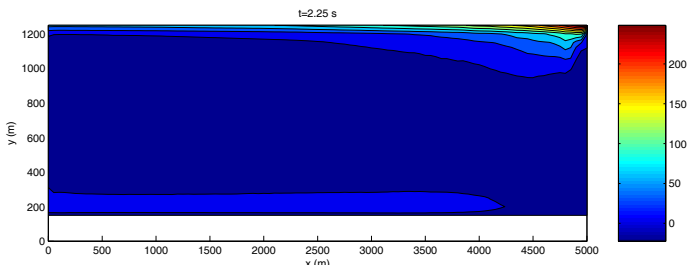

(e) $t=3.25 \mathrm{sec}$

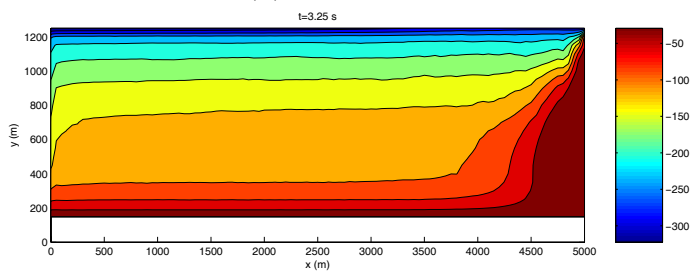

(g) $t=4.75 \mathrm{sec}$

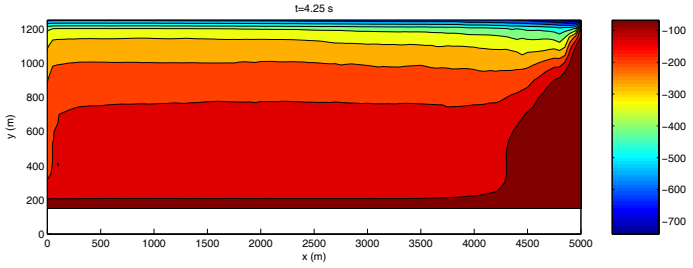

(b) $t=1.0 \mathrm{sec}$

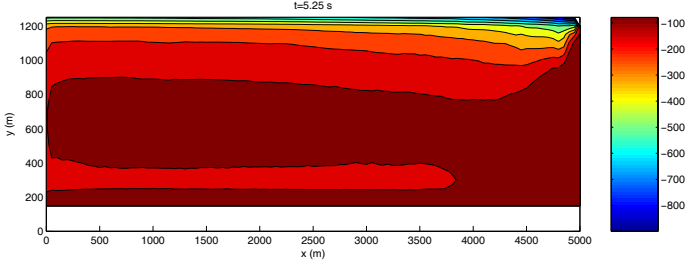

(d) $t=2.5 \mathrm{sec}$

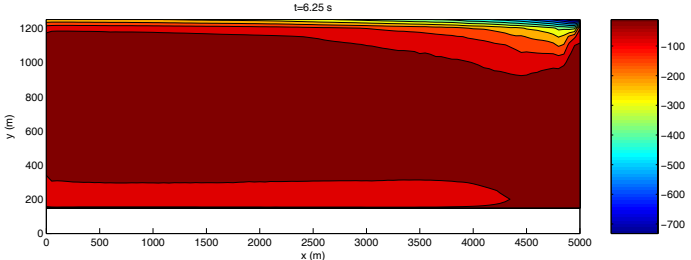

(f) $t=4.0 \mathrm{sec}$

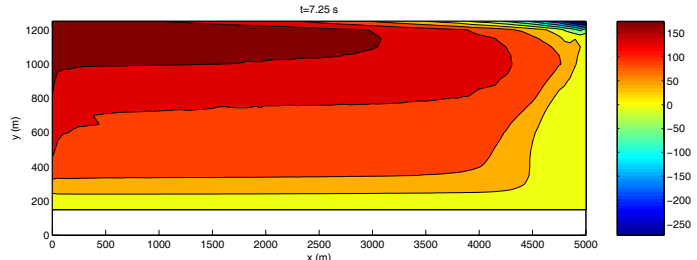

(h) $t=5.5 \mathrm{sec}$

Figure 3: Contour of the wave-induced pore pressure in a flat seabed. $\left(S_{r}=0.95, z=-5 \mathrm{~m}\right)$ 


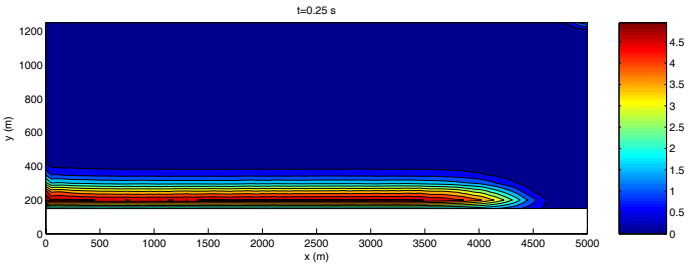

(a) $t=0.25 \mathrm{sec}$

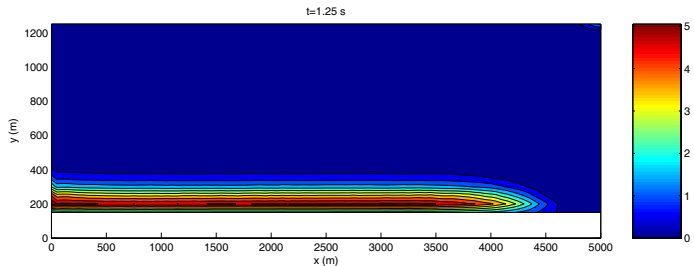

(c) $t=1.75 \mathrm{sec}$

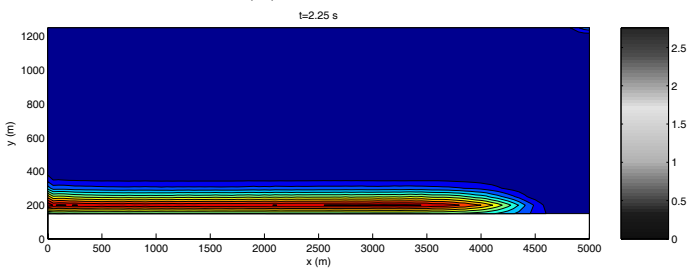

(e) $t=3.25 \mathrm{sec}$

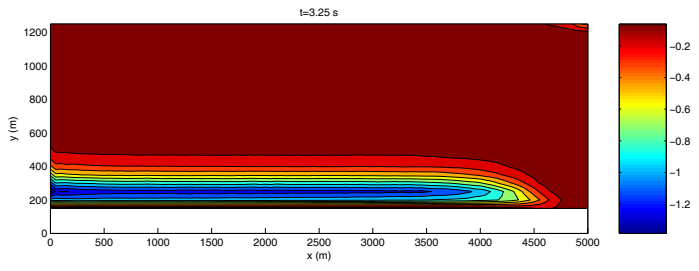

(g) $t=4.75 \mathrm{sec}$

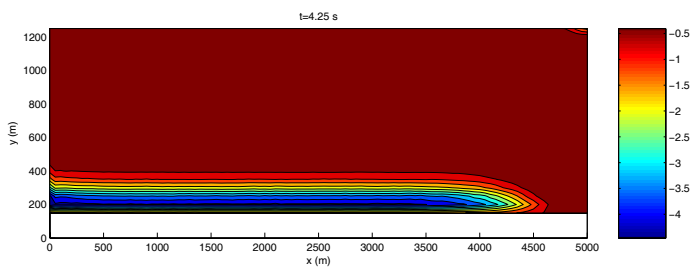

(b) $t=1.0 \mathrm{sec}$

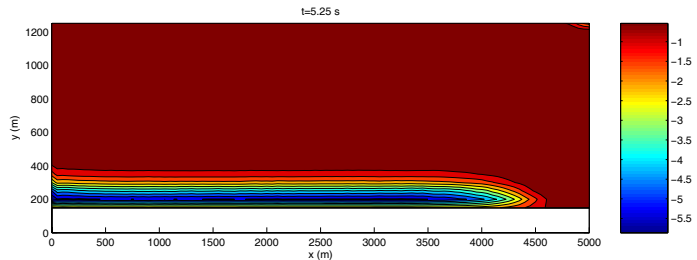

(d) $t=2.5 \mathrm{sec}$

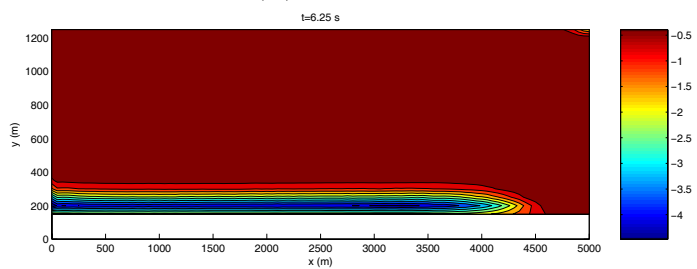

(f) $t=4.0 \mathrm{sec}$

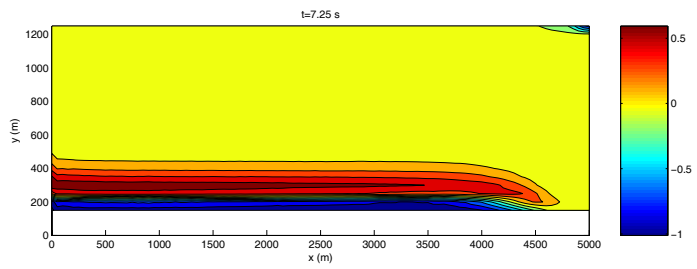

(h) $t=5.5 \mathrm{sec}$

Figure 4: Contour of the wave-induced pore pressure in a sloping seabed. $\left(S_{r}=0.95, z=-1 \mathrm{~m}\right.$, slope $=1 / 10)$ 


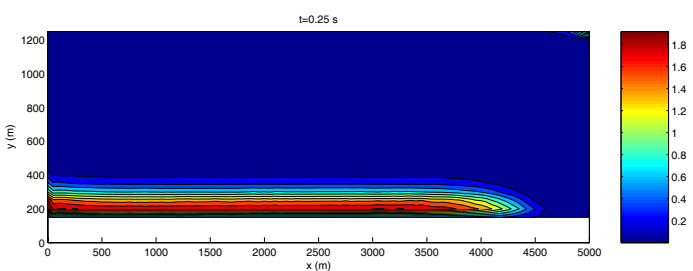

(a) $t=0.25 \mathrm{sec}$

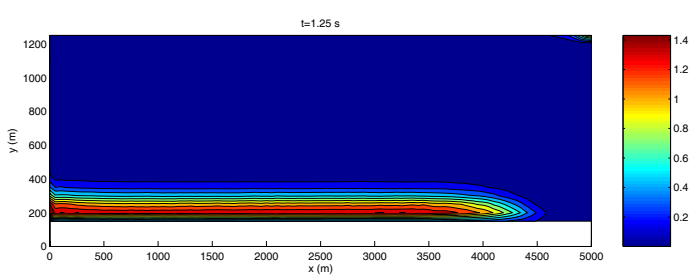

(c) $t=1.75 \mathrm{sec}$

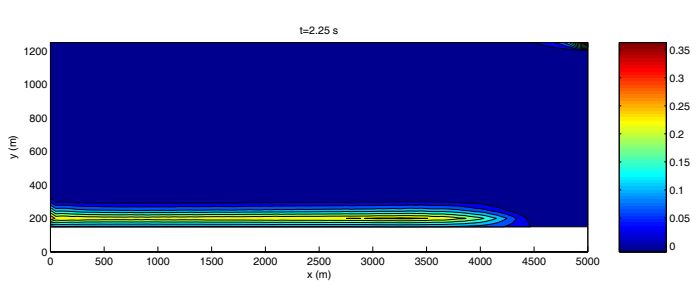

(e) $t=3.25 \mathrm{sec}$

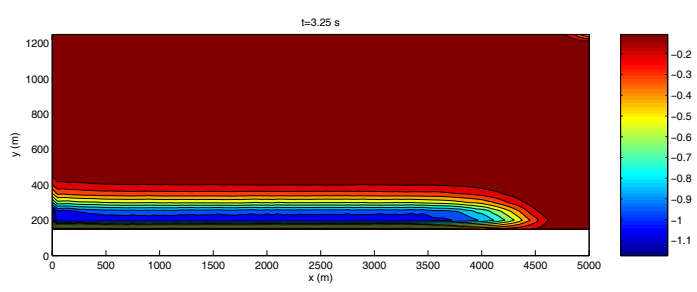

(g) $t=4.75 \mathrm{sec}$

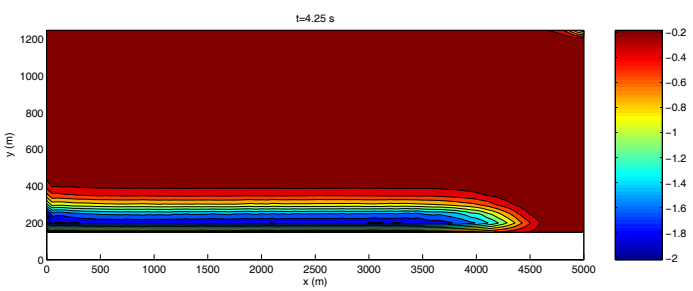

(b) $t=1.0 \mathrm{sec}$

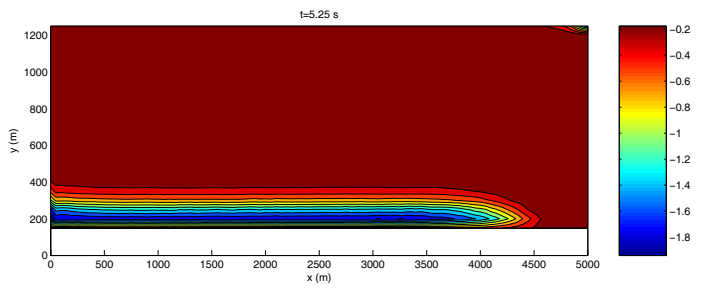

(d) $t=2.5 \mathrm{sec}$

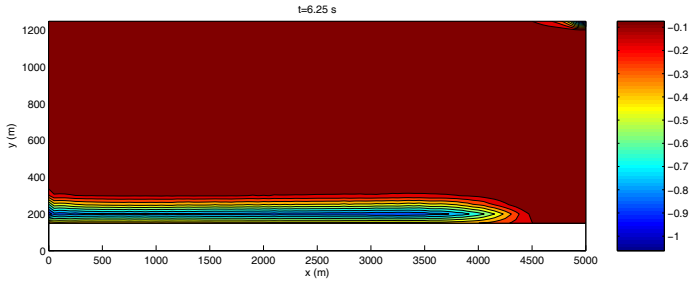

(f) $t=4.0 \mathrm{sec}$

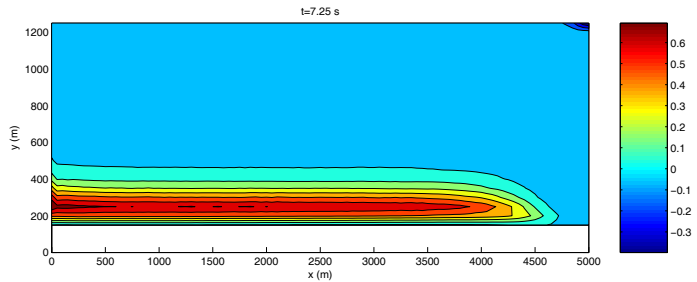

(h) $t=5.5 \mathrm{sec}$

Figure 5: Contour of the wave-induced pore pressure in a sloping seabed. $\left(S_{r}=0.95, z=-5 \mathrm{~m}\right.$, slope $\left.=1 / 10\right)$ 


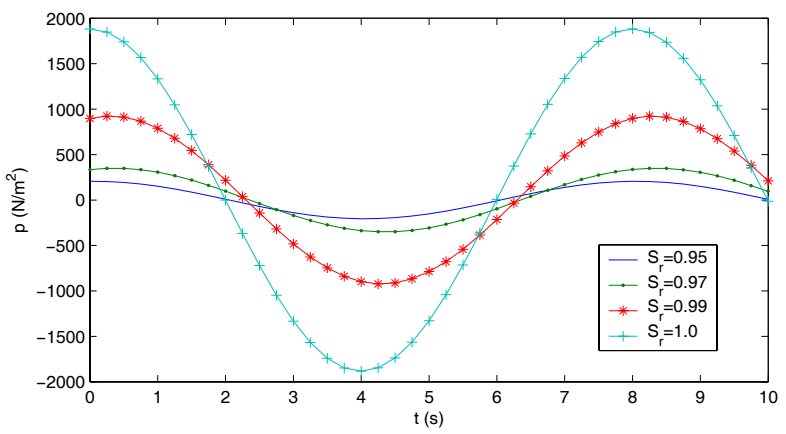

(a) a flat seabed

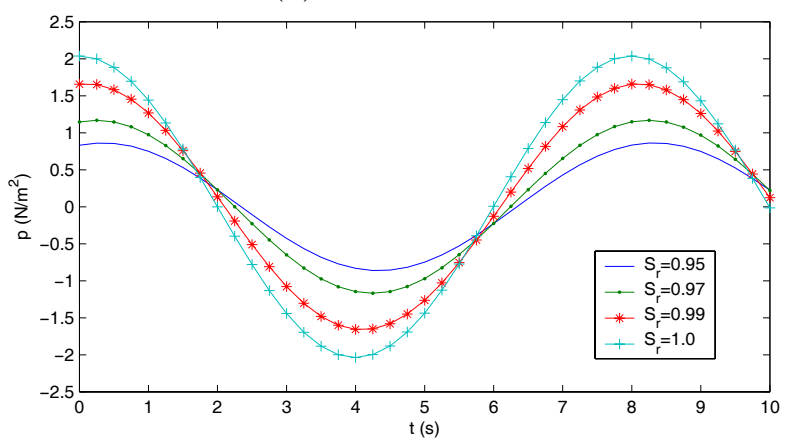

(b) a sloping seabed (slope=1/10)

Figure 6: Distribution of the wave-induced pore pressure versus time in a (a) flat seabed and (b) sloping seabed $($ slope $=1 / 10)$ for various degrees of saturation.

\subsection{Effects of the degree of saturation}

It is common to have gas/air within marine sediments, which results in an unsaturated seabed. It is noted that most marine sediments may display a certain degree of saturation, but the degree of saturation varies between 0.95 and 1.0 (Jeng, 1997). In this section, we investigate the influence of the degree of saturation on soil response parameters.

Figure 6 illustrates a comparison of wave-induced pore pressures in both flat and sloping $(\operatorname{slope}=1 / 10)$ seabeds. The distributions of pore pressure $(p)$ versus time $(t)$ for various degrees of saturation $\left(S_{r}\right)$ are plotted in the figure. Figure 6(a) is for a flat seabed, while 6(b) is for a sloping seabed. In general, the amplitude of pore pressure (i.e., $|p|$ ) increases as $S_{r}$ increases in both seabeds. Compared with the flat seabed, the magnitude of pore pressure in a sloping seabed is about three orders smaller, as shown in Figure 6(a) and (b).

The distribution of the wave-induced effective normal stresses and shear stress in a sloping seabed are illustrated in Figure 7. In general, the degree of saturation significantly affect the wave-induced effective normal stresses (Figures 7(a)-(c)), but insignificant in shear stress (Figure 7(d)). The wave-induced effective normal stresses in the $x$-direction $\left(\sigma_{x}^{\prime}\right)$ increases as the degree of saturation increases near the wave crests, as shown in Figure 7(a). However, an opposite distribution is observed for other soil response parameters $\left(\sigma_{y}^{\prime}, \sigma_{z}^{\prime}\right.$ and $\left.\tau_{x z}\right)$ in Figures $7(\mathrm{~b})-(\mathrm{d})$. It is also observed in figure 7 , there is a phase lag in the distribution of $\sigma_{y}^{\prime}$ and $\sigma_{z}^{\prime}$, implies that the maximum pore pressure may not occurs at the phase of water wave crests. This is because the pore fluid is transported in a two-phase mixture medium, while ocean wave is in one single medium.

\subsection{Effects of shear modulus}

The shear modulus is the parameter describing the hardness of a material. For marine sediments, the typical value of the shear modulus for gravel is $5 \times 10^{7} \mathrm{~N} / \mathrm{m}^{2}$, while sandy seabed vary between $5 \times 10^{6}$ and $10^{7} \mathrm{~N} / \mathrm{m}^{2}$.

As shown in Figure $8(\mathrm{a})$, the pore pressure in a soft flat seabed $\left(G=5 \times 10^{6} \mathrm{~N} / \mathrm{m}^{2}\right)$ display a 90 degree phase lag, compare with other materials. However, in a sloping seabed, an obvious phase lag is 


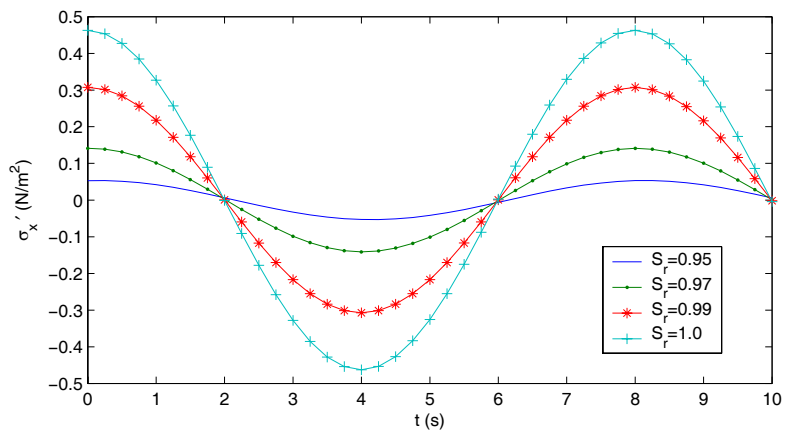

(a) $\sigma_{x}^{\prime}$

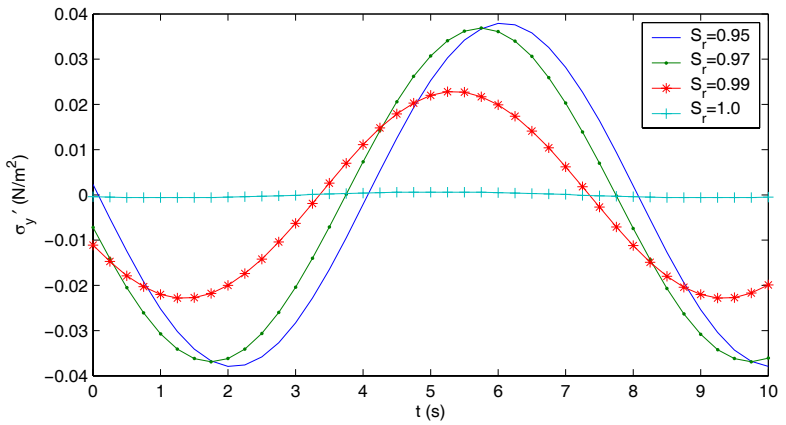

(b) $\sigma_{y}^{\prime}$

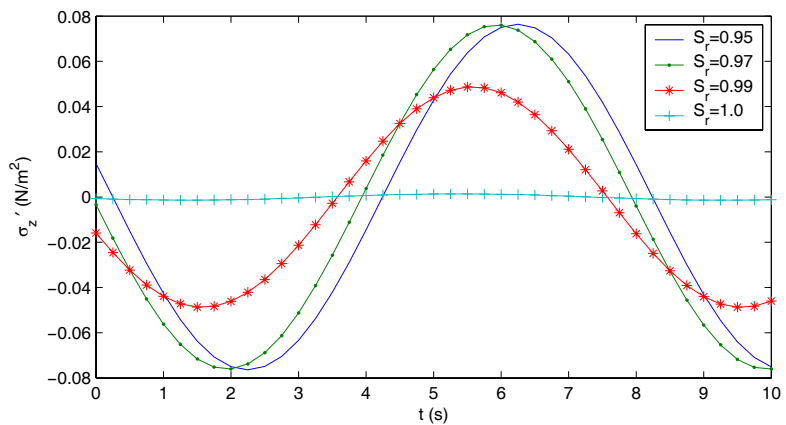

(c) $\sigma_{z}^{\prime}$

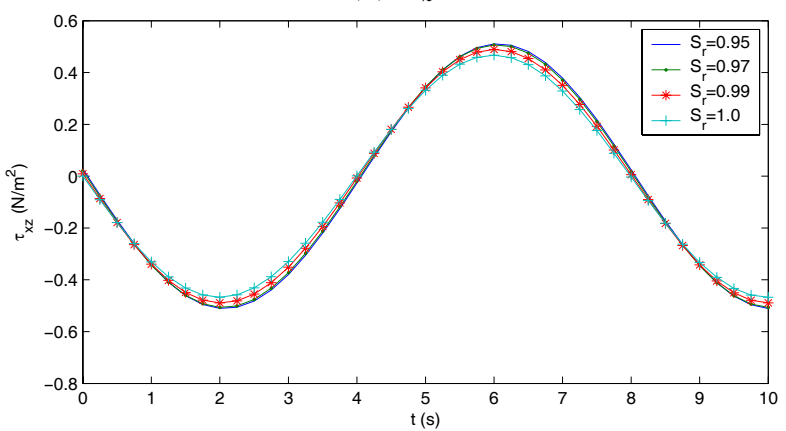

(d) $\tau_{x z}$

Figure 7: Distribution of the wave-induced stresses versus time in a sloping seabed for various degrees of saturation $($ slope $=1 / 10)$. 


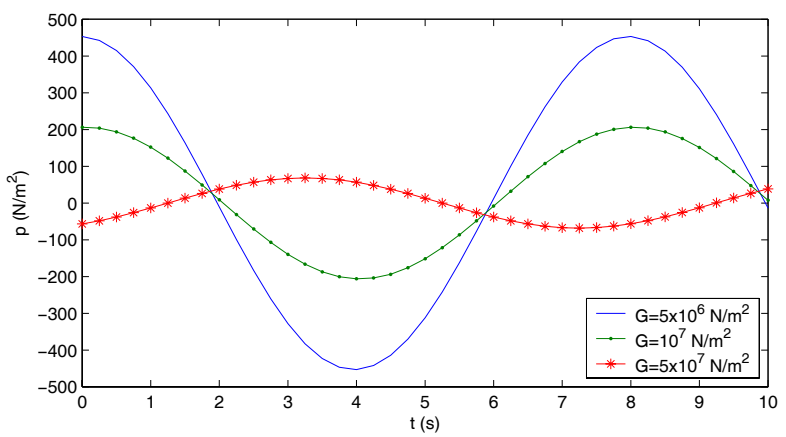

(a) a flat seabed

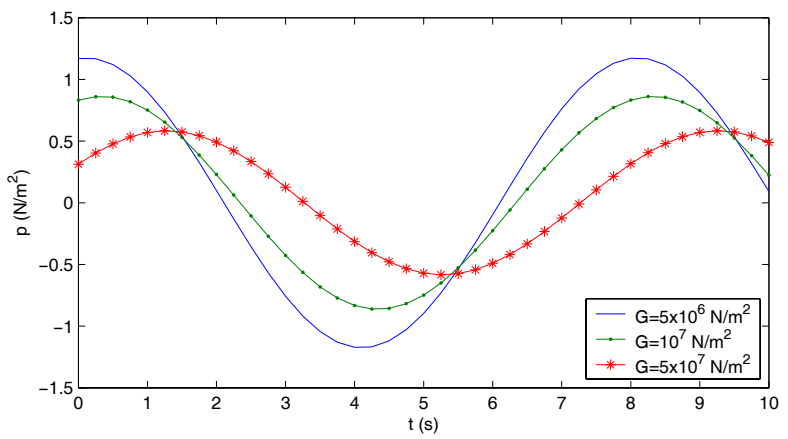

(b) a sloping seabed (slope=1/10)

Figure 8: Distribution of the wave-induced pore pressure versus time in a (a) flat seabed and (b) sloping seabed $($ slope $=1 / 10)$ for various values of shear modulus.

only observed in a harder seabed (such as a gravelled seabed, $G=5 \times 10^{7} \mathrm{~N} / \mathrm{m}^{2}$ ), as shown in Figure 8(b). Basically, the pore pressure increases as shear modulus increases near the wave crests. That is, the wave-induced pore pressure in a softer seabed is larger that in a coasrser seabed. It is also noted that the pore pressure in a sloping seabed is much smaller than that in a flat seabed.

The distributions of the wave-induced effective normal stresses and shear stress versus time are plotted in Figure 9. In general, the stresses increases as shear modulus increases, expect $\sigma_{x}^{\prime}$. Again, the shear modulus does not significantly affect the wave-induced shear stresses in a sloping seabed, as shown in Figure $9(\mathrm{~d})$.

\subsection{Effects of permeability}

Permeability is a measure of how fast the pore fluid transfer within porous medium. The typical values of permeability in sandy seabed vary between $10^{-2}$ and $10^{-4} \mathrm{~m} / \mathrm{sec}$, while it is about $10^{-1} \mathrm{~m} / \mathrm{sec}$ in a gravelled seabed. Figure 10 illustrates the distribution of pore pressure versus time for both flat and sloping seabeds. As shown in the figure, the pore pressure increases as permeability increases. This implies that pore fluid will create higher pressure within pore between solid particles in a coarser seabed.

Figure 11 illustrates the distribution of the wave-induced stresses versus time for various permeabilities. It is clear that the vertical effective normal stress $\left(\sigma_{z}^{\prime}\right)$ in a gravelled seabed $\left(K_{x}=K_{z}=10^{-1}\right.$ $\mathrm{m} / \mathrm{sec}$ ) is one-order larger than that in sandy seabeds. Furthermore, in general, the wave-induced stresses increases as the permeability increases near wave crests. However, the influence of permeability on the wave-induced shear stress is insignificant, as shown in Figure 11(d).

\subsection{Effects of slopes}

To further investigate the effects of the seabed slopes on the wave-induced soil response, we choose four different slopes, 1/100,1/50,1/20 and 1/10, together with a flat seabed. As shown in Figure 12, the wave-induced pore pressure increases as the slope of the seabed decreases. This implies that the waveinduced pore pressure in a flat seabed is greater that in a sloping seabed. The previous solution for a flat seabed (Jeng, 1997a) over-estimates the wave-induced pore pressures. 


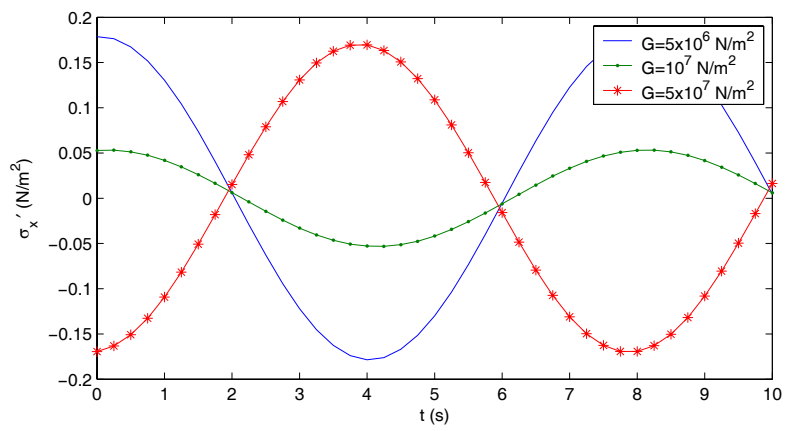

(a) $\sigma_{x}^{\prime}$

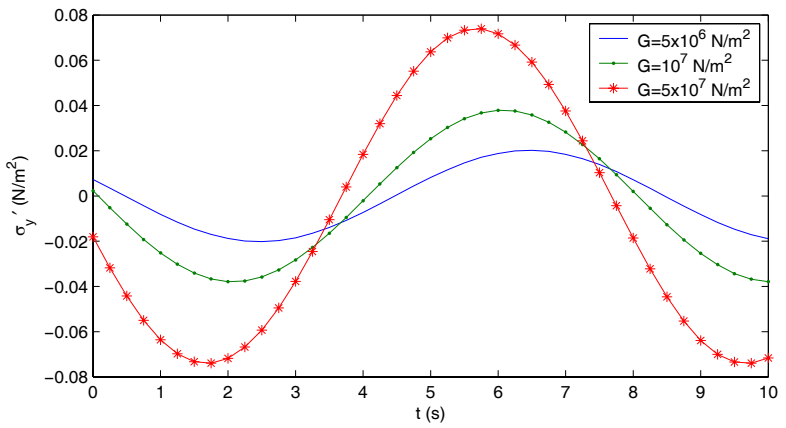

(b) $\sigma_{y}^{\prime}$

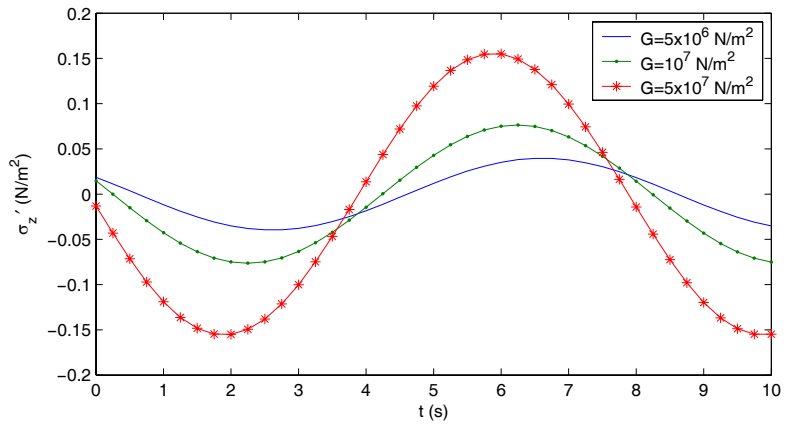

(c) $\sigma_{z}^{\prime}$

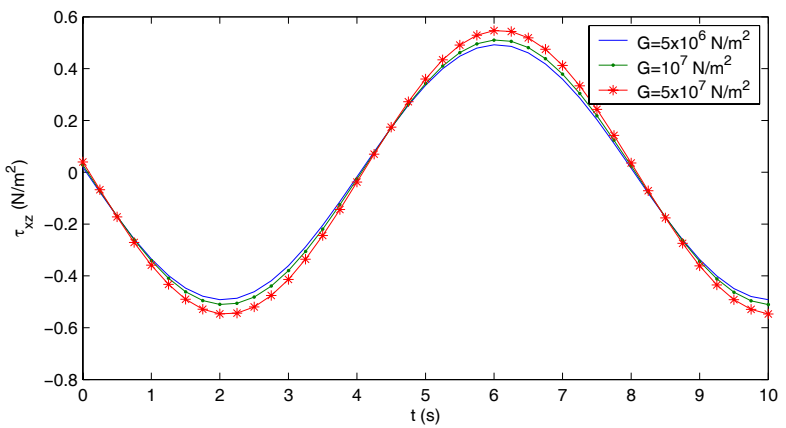

(d) $\tau_{x z}$

Figure 9: Distribution of the wave-induced stresses versus time in a sloping seabed for various values of shear modulus (slope $=1 / 10$ ). 


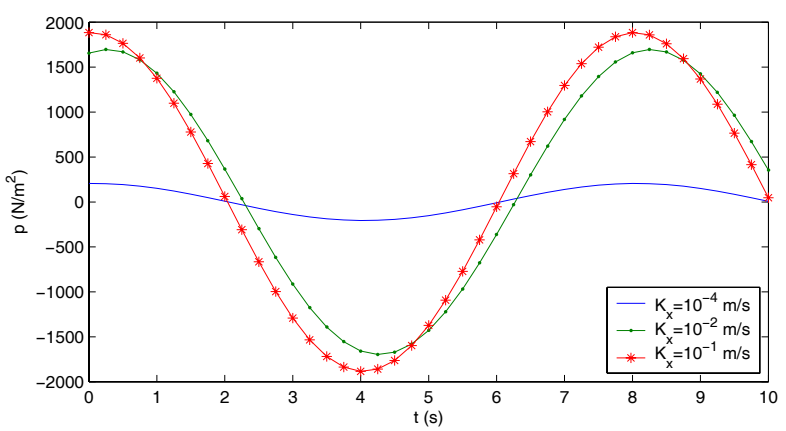

(a) a flat seabed

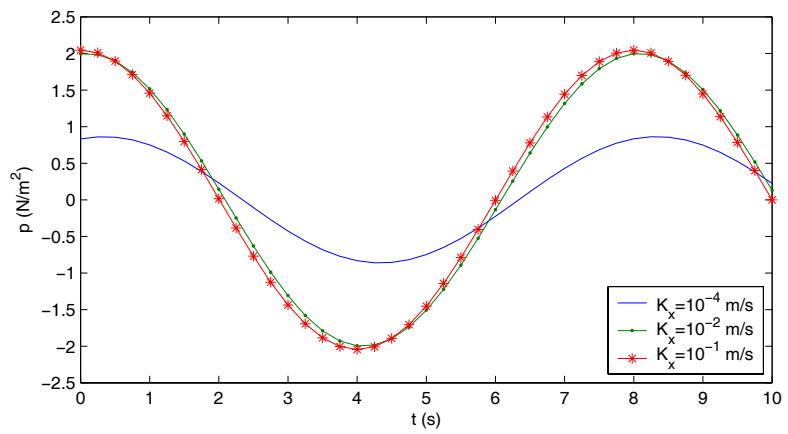

(b) a sloping seabed (slope=1/10)

Figure 10: Distribution of the wave-induced pore pressure versus time in a (a) flat seabed and (b) sloping seabed (slope $=1 / 10$ ) for various values of soil permeability.

\section{Conclusions}

In this study, an integrated three-dimensional model for wave-induced seabed response has been established. Both flat and sloping seabeds have been considered in the new model. Based on the numerical results, the following conclusions can be drawn.

(1) Generally speaking, the magnitude of the wave-induced soil response, including pore pressure and stresses in a sloping seabed is much smaller than that in a flat seabed.

(2) The wave-induced pore pressure and effective normal stresses are significantly affected by soil parameters, but shear stresses are only insignificantly affected by soil parameter.

(3) Besides the soil parameters, the slope of a seabed is another important parameter. Numerical results indicate that the wave-induced pore pressure decreases as the slope of a seabed increases.

In this paper, only the non-breaking wave loading is considered. The breaking wave-induced seabed response (including soil response and liquefaction) in a three-dimensional domain will be further investigated in Jeng and Zhang (2004).

\section{Acknowledgements}

The second author is grateful for the support of Australian Research Council Large Grant Scheme (\#A00104092).

\section{References}

Barends, F. B. J (1991), Interaction between ocean waves and sea-bed. Proceedings of the International Conference on Geotechnical Engineering for Coastal Development-Theory and Practice on Soft Ground (Geot-Coastal'91), Yokohama, Japan, 2, 1091-1108 


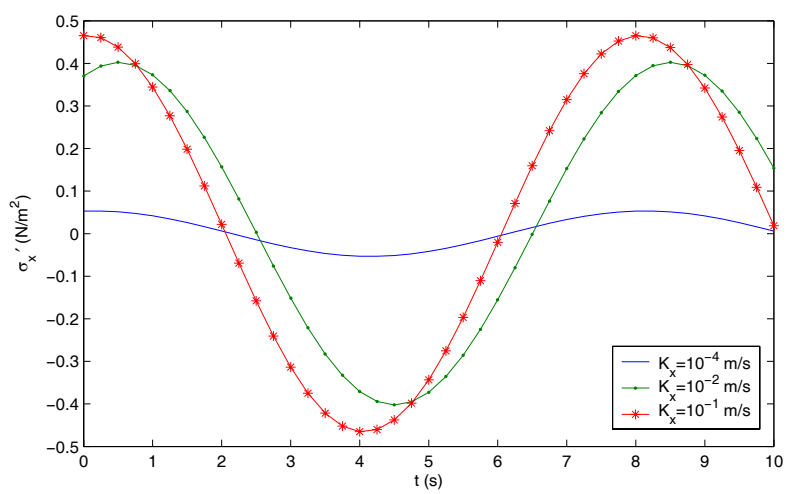

(a) $\sigma_{x}^{\prime}$

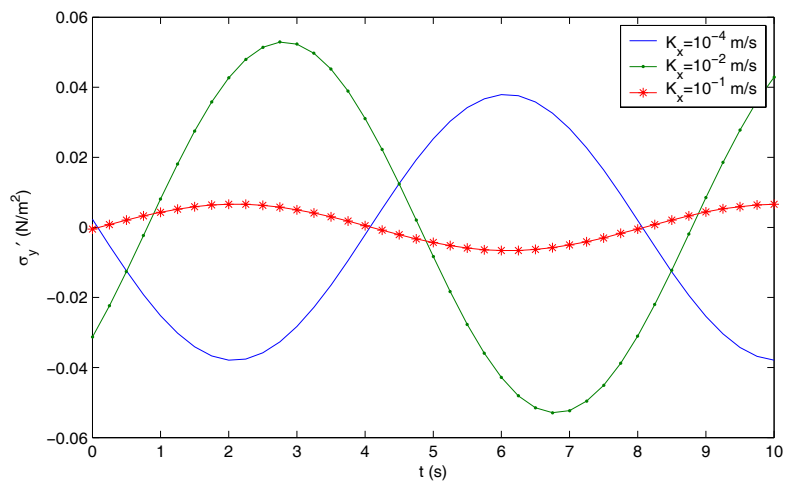

(b) $\sigma_{y}^{\prime}$

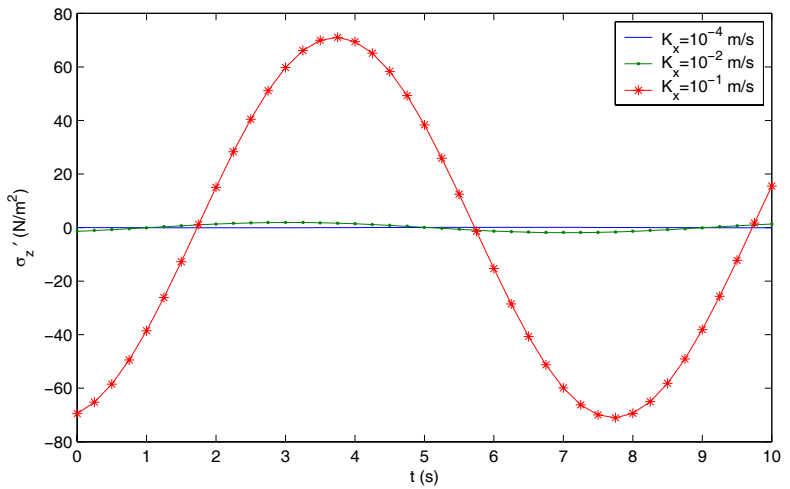

(c) $\sigma_{z}^{\prime}$

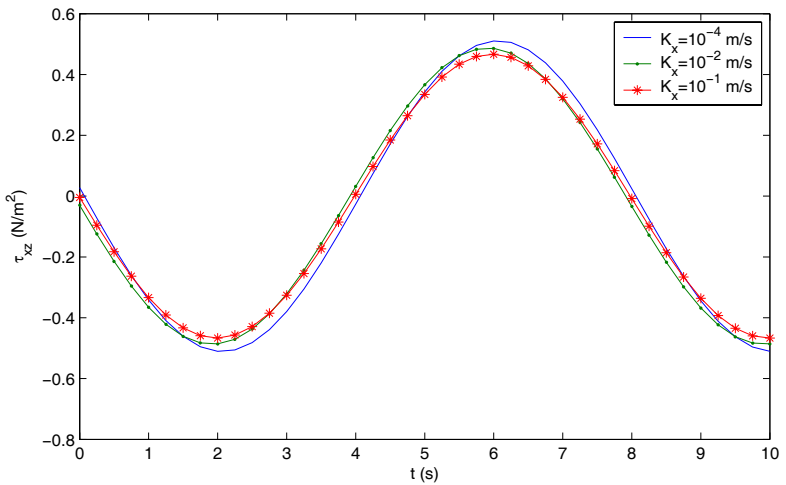

(d) $\tau_{x z}$

Figure 11: Distribution of the wave-induced stresses versus time in a sloping seabed for various values of soil permeability $($ slope $=1 / 10)$. 


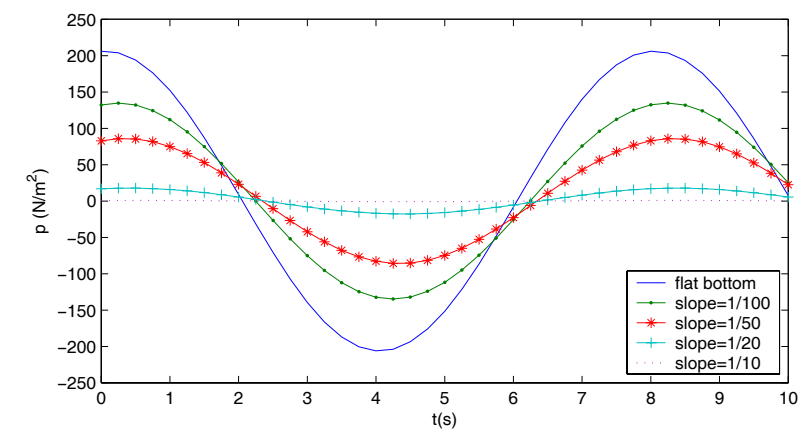

Figure 12: Effects of beach slopes on the wave-induced pore pressure.

Battjes, J. A. and Janssen, J. P. F. M. (1978). Energy loss and set-up due to breaking of random waves. Proceedings 16th International Conference on Coastal Engineering, A.S.C.E., 569-587.

Bea, R.G., Wright, S. G., Sircar, P. and Niedoroda, A. W (1983), Wave-induced slides in South Pass block 70, Mississippi Delta. Journal of Geotechnical Engineering, A.S.C.E., 109(1), 619-644.

Biot, M. A. (1941). General theory of three-dimensional consolidation. Journal of Applied Physics, $12(2), 1550164$.

Booij, N.C., Ris, R.C., Holthuijsen, L.H., (1999). A third-generation wave model for coastal regions. Part I, Model description and validation. Journal of Geophysical Research, 104 (C4), 7649-7666.

Cha, D. H., (2003). Mechanism of Ocean Waves Propagating over a Porous Seabed. MPhil Thesis, Griffith University, Australia.

Cha, D. H., Jeng, D.-S., Rahman, M. S., Sekiguchi, H., Zen, K. and Yamazaki, H. (2002). Effects of dynamic soil behaviour on the wave-induced seabed response. International Journal of Ocean Engineering and Technology, 16(5), 21-33.

Christian JT, Taylor PK, Yen JKC and Erali DR (1974), Large diameter underwater pipeline for nuclear power plant designed against soil liquefaction. Proceeding of Offshore Technology Conference, Dallas, 597-606.

Eldenerky, Y. and Battjes, J. A. (1995). Parameterization of triad interaction in wave energy models. Proceedings Coastal Dynamics Conference'95, Gdansk, Poland, 140-148.

Eldenerky, Y. and Battjes, J. A. (1996). Spectral modelling of wave breaking: Application to Boussinesq equations. Journal of geophysical Research, 101(C1), 1253-1264.

Holthuijsen, L.H., Booij, N., Ris, R.C., Haagsma, I.J.G., Kieftenburg, A.T.M.M., Kriezi, E.E. (2003). SWAN Cycle III Version 40.20 User Manual. Delft University of Technology, The Netherlands.

Jeng, D.-S., (1997). Wave-induced seabed instability in front of a breakwater. Ocean Engineering 24 (10), 887-917.

Jeng, D.-S. and Cha, D. H. (2003). Effects of dynamic soil behaviour and wave non-linearity on the wave-induced pore pressure and effective stresses in porous seabed. Ocean Engineering, 30(16), 2065-2089.

Jeng, D.-S. and Lin, Y. S., (1997). Non-linear waves-induced response in a cross-anisotropic seabed with variable soil characteristics. International Journal for Numerical and Analytical Methods in Geomechnics, 21(1), 15-42.

Jeng, D.-S. and Zhang, H. (2004). An integrated 3-D model of wave-induced soil response in a porous seabed. II: breaking waves. Ocean Engineering (in preparing).

Jeng, D.-S., Lee, T. L., Chien, L.K., Rahman, M. S., Oh, Y. N. and Hsu, J. R. C. (2004). Analytical assessment of non-linear wave-induced Liquefaction. Geotechnical Engineering Journal, SEAGS, (accepted). 
Lin, Y. S. and Jeng, D.-S., (2000). Short-crested wave-induced liquefaction in porous seabed. Journal of Geotechnical and Geoenvironmental Engineering, ASCE, 126(5), 481-494.

Liu, P. L. F., (1973). Damping of water waves over porous bed. Journal of Hydraulic Division, A.S.C.E., 99(12), 2263-2271.

Lundgren, H., Lindhardt, J. H. C. and Romhild, C. J. (1989), Stability of breakwaters on porous foundation. Proceedings 12th International Conference Soil Mechanics and Foundation Engineering, $1,451-454$.

Mei, C. C. and Foda, M. A. (1981). Wave-induced soil response in a fluid-filled poro-elastic solid with a free surface-a boundary layer theory. Geophysical Journal of Royal Astron Society, 66, 596-631.

Moshagen, H. and Torum, A. (1975). Wave induced pressures in permeable seabeds. Journal of Waterway, Port, Coastal Engineering Division, A.S.C.E., 101(1), 49-57.

Mynett, A. E. and Mei, C. C., (1982). Wave-induced stresses in a saturated poroelastic seabed beneath a rectangular caisson. Geotechnique, 32, 235-248.

Nye, T. and Yamamoto, T. (1994). Field test of buried ocean-wave directional spectrometer system. Journal of the Waterway, Port, Coastal and Ocean Engineering, A.S.C.E., 120(5), 451-466.

Putnam, J. A. (1949). Loss of wave energy due to percolation in permeable sea bottom. Trans. American Geophysical Union, 30(3), 349-356.

Ris, R.C., Holthuijsen, H. AND Booij, N., (1999). A third-generation wave model for coastal regions, Part II, Verification. Journal of Geophysical Research, 104 (C4), 7667-7681.

Shemdin, P., Hasselmamn, K., Hsiao, S. V., Herterich, K. (1978). Non-linear and linear bottom interaction effects in shallow water. In: Turbulent Fluxes through the Sea Surface, Dynamics and Prediction, NATO Conference, Ser, V, 1, 347-372.

Silvester R and Hsu JRC (1989), Sines Revisited. Journal of Waterways, Port, Coastal and Ocean Engineering, A.S.C.E., 115(3), 327-344.

Silvester R and Hsu JRC (1993), Coastal Stabilization. PTR Prentice-Hall Inc., NJ.

Verruijt, A. (1969). Elastic storage of aquifers, In: Flow Through Porous Media, EJM De Wiest (ed), Academic Press, New York, 331-376.

Yamamoto, T., H. L. Koning, H. Sellmejjer, E. V. Hijum, (1978). On the response of a poro-elastic bed to water waves. Journal of Fluid Mechanics, 87, 193-206.

Yamamoto T and Trevorrow M (1991), Experimental verifications of bottom shear modulus profiler (BSMP) method. Proceedings of the International Conference on Geotechnical Engineering for Coastal Development-Theory and Practice on Soft Ground (Geot-Coastal 91), Yokohama, Japan, 1,123-128.

Yamamoto T and Turgut A (1988), Acoustic wave propagation through porous media with arbitrary pore size distributions. Journal of Acoustical Society of America, 83(5), 1744-1751. 